\title{
Remote ENSO forcing versus local air-sea interaction in QTCM: a sensitivity study to intraseasonal variability
}

\author{
D. Gushchina ${ }^{1}$, B. Dewitte ${ }^{2}$, and S. Illig ${ }^{2}$ \\ ${ }^{1}$ Moscow State University, Geographical Faculty, Vorobyevy gory, 119992, Moscow, Russia \\ ${ }^{2}$ Laboratoire d'Etude en Geophysique et Oceanographie Spatiale, 14, av. Ed. Belin, Toulouse, 31400, France
}

Received: 11 July 2005 - Revised: 23 January 2006 - Accepted: 24 January 2006 - Published: 30 March 2006

\begin{abstract}
The skill of a newly designed global atmospheric model of intermediate complexity - QTCM (for quasi-equilibrium tropical circulation model) in simulating the teleconnections is investigated. The role of the ENSO remote forcing over the Pacific surrounding regions is emphasized from sensitivity experiments to critical parameters of the model. The role of the tropical intraseasonal variability (ITV) on the simulated ENSO teleconnection pattern is estimated using the methodology proposed by Lin et al. (2000) allowing to damp the energy of ITV in the model. The reduction of intraseasonal variability allows emphasizing the forced response of the atmosphere and eases the detection of local coupled atmosphere-ocean patterns. It was shown that the simulated ITV has an impact on the ENSO teleconnection pattern both in the mid-latitudes and in regions of ascending and descending branches of Walker circulation cells in the tropics.
\end{abstract}

\section{Introduction}

The problem of teleconnection in climate studies is complex. The El Niño Southern Oscillation (ENSO) is considered as a main source of the interannual variability in many remote regions outside the tropical Pacific (see Trenberth et al. (1998) for the review of ENSO teleconnections). ENSO alters the sources of atmospheric heat that then affect atmospheric circulation and climate on a global scale (Wang, 2002). Among the most well known remote impacts are the changes in atmospheric circulation over the northern Pacific and North America and associated sea surface temperature (SST) anomalies in the North Pacific (Wallace and Gutzler, 1981; Lau, 1997), as well as above normal SST and near-surface air temperature at land stations in the Indian and Atlantic Oceans during the warm phase of ENSO (Enfield and Mayer, 1997; Yulaeva and Wallace, 1994). These changes in surface temperature

Correspondence to: D. Gushchina

(gushchina@geogr.msu.su) are in turn associated with droughts in the northeast region of Brazil (Hastenrath et al., 1997), eastern equatorial Africa, India, drier than normal conditions in Indonesia and Australia (Rasmusson and Carpenter, 1983; Ropelewski and Halpert, 1987) and floods in Peru and Ecuador (Wallace et al., 1998). The local air-sea interactions are also a major contributor to the seasonal to interannual variability (Marshall et al., 2001; Chang et al., 2000; Webster et al., 1998). The estimation of remote versus local forcing is difficult to obtain from observation alone. Model experiments are required to separate the remote forced variability from the locally forced one (Liu et al., 2004). Therefore representing correctly teleconnection and local interaction in models is a top-priority issue because of the non-linear interaction between local and remote forcings. In particular, ocean-atmosphere coupled models that resolve explicitly the local air-sea equilibrium can provide a meaningful material for the understanding of the teleconnection mechanism. There are a large number of studies using General Circulation Models (GCMs) to simulate the atmospheric response to tropical SST anomalies on seasonal and interannual timescales (Lau, 1985; Barnett et al., 1994; Kumar and Hoerling, 1998; Saravanan and Chang, 2000). Whereas the Global Coupled General Circulation models are the most complete in terms of physics, they are however the ones that present the most severe biases, especially outside the tropical Pacific. At the same time the intermediate circulation models can be useful tools for investigating the teleconnection processes when they demonstrate the good skill in simulating the ENSO-like variability and its remote impacts. Not only the simplified physics often eases the interpretation of the simulation, but they are also computationally cost effective which allows for sensitivity experiments.

The tropical intraseasonal variability was shown to play an important role in ENSO forcing (Moore and Kleeman, 1999) as well as in ENSO teleconnections (Wu and Shubert, 2002). In the intraseasonal variability one usually distinguishes two modes: the coherent variability (Madden-Julian like oscillations (Madden and Julian, 1994) and stochastic variability (random weather noise). The influence of random weather 


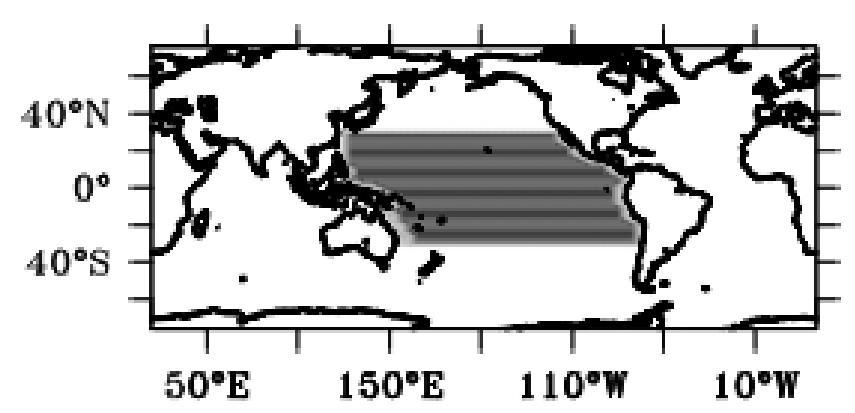

Fig. 1. Zone of interannual SST Anomaly forcing for the PAC experiment.

noise as well as Madden-Julian oscillation on the simulated ENSO teleconnection still needs to be estimated. In this study we investigate the skill of a newly designed global intermediate atmospheric model in simulating the teleconnections. The role of the ENSO remote forcing over the Pacific surrounding regions is emphasised from sensitivity experiments to critical parameters of the model. Of particular interest is the role of intraseasonal variability on the simulated ENSO teleconnection pattern. The model used in this study is QTCM developed by David Neelin and his team at UCLA. This model is not only skilful in simulating some aspect of the ENSO teleconnection but, due to its formulation, it allows to 'turn off or on' the model intraseasonal variability, which avoids carrying out numerous experiments to derive ensemble mean.

This paper is organized as follows. Section 2 briefly describes the data and the intermediate atmospheric model. In Sect. 3 the comparison between the experiments with global forcing and Pacific forcing are presented and analysed. Section 4 describes the characteristics of the simulated intraseasonal variability and investigate its impact on the ENSO teleconnection. Section 5 summarizes the results.

\section{Data and model}

\subsection{The data}

The NCEP/ NCAR reanalysis data set (Kalnay et al., 1996) is used for zonal and meridional wind at 200,500 and $850 \mathrm{hPa}$, precipitation, outgoing longwave radiation (OLR) and zonal wind stress (TX). For comparison with the QTCM outputs, data were bilinearly interpolated from the NCEP/NCAR grid $\left(2.5^{\circ} \times 2.5^{\circ}\right)$ to the model grid $\left(4^{\circ} \times 1.875^{\circ}\right)$. The Reanalysis data cover the period from January 1948 until December 1997 for U200, U850, V200 and V850 and from January 1958 until December 1997 for other variables. These fields are referred to as "observations" in the followings although strictly speaking they are not observed data but results from a combination of observations and model simulations.

Model forcing are the SST and Sea Ice Extension from the two GISST (Global Sea Ice and Sea Surface Tempera- ture) reconstructed datasets (Rayner et al., 1997) namely the GISST 2.3 from 1947 to 1982 and the new released GISST 3.0 package from 1983 to 1998 .

\subsection{The QTCM model}

The QTCM model (for Quasi-Equilibrium Tropical Circulation Model) has been proposed recently to fill the niche between the GCMs and simpler models. It is a primitive equation-based intermediate-level atmospheric model that focused on simulating the tropical atmosphere. The constraints placed on the flow by quasi-equilibrium parametrization are used to calculate typical vertical structures of temperature, moisture and winds. Being more complicated than a simple model, the model has full non-linearity, includes a radiative-convective feedback package, and a simple land soil moisture routine. Topography is not taken explicitly into account but an inhomogeneous surface roughness is used. For its convective parameterization, this model uses the Betts-Miller (1986) moist convective scheme, a scheme which is also used in some GCMs. Model formulation is described in Neelin and Zeng (2000) and model implementation is described in Zeng et al. (2000). Zeng et al. (2000) show results indicating that this intermediate-level model does a reasonable job in simulating tropical climatology and ENSO variability. The model also maintains intraseasonal oscillations which some of characteristics resemble the realworld intraseasonal oscillations (Lin et al., 2000).

In this study, considering that SST anomalies in the Atlantic ocean have finer meridional scales than in the Pacific, a version of QTCM 2.3 with higher longitudinal-latitudinal resolution was used. The horizontal resolution is $4^{\circ} \times 1.875^{\circ}$ instead of $5.625^{\circ} \times 3.75^{\circ}$. This version of the model was developed and used in a recent work (Illig and Dewitte, 2006).

The anomalies for observations and QTCM are derived by subtracting the monthly climatologies calculated over the period 1958-1997.

\section{Role of remote Pacific forcing in the interannual trop- ical variability}

In this study, we aim to analyze local versus remote effect via teleconnections in the atmosphere between the basins. In particular we are interested in the remote forcing produced by the anomalous SST signal in the tropical Pacific region. For such kind of ENSO teleconnection studies, model runs in which SST anomalies are specified in individual areas are usually performed (Su et al., 2001).

\subsection{Methodology and model experiments}

A 50-year model run was carried out with QTCM, with the monthly GISST dataset as boundary forcing interpolated onto the model grid. The simulation starts the 1 January of 1948, the first simulated year being discarded in the subsequent analyses to account for the adjustment time of the 
(a)

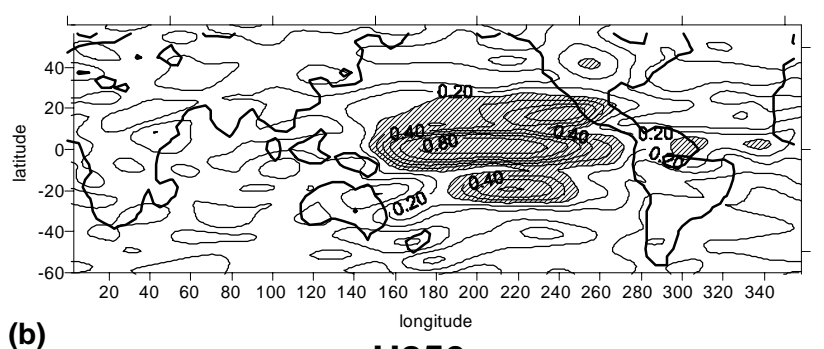

(b)

U850

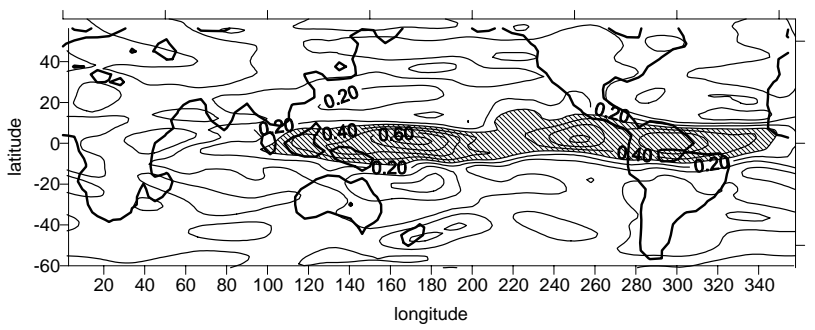

(c)

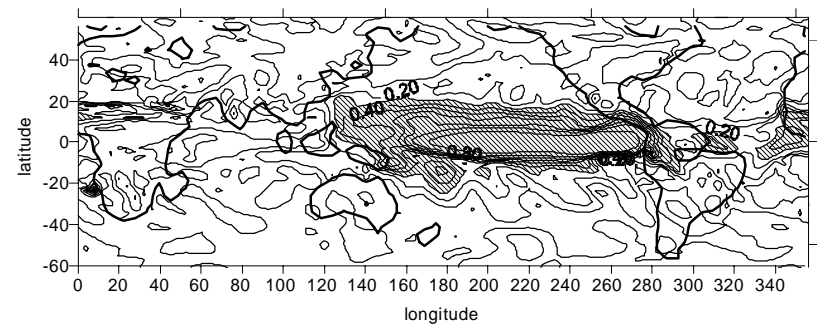

(d)

U200

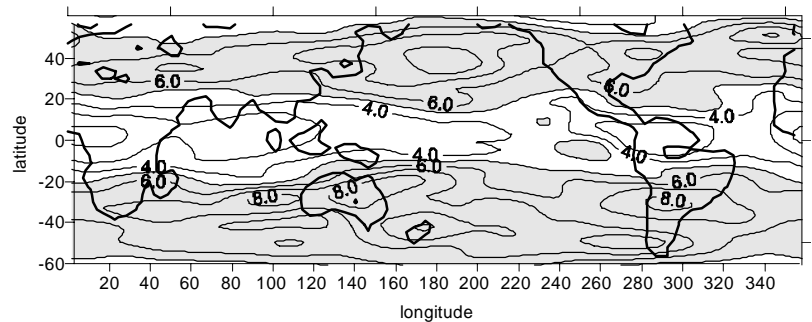

(e)

U850

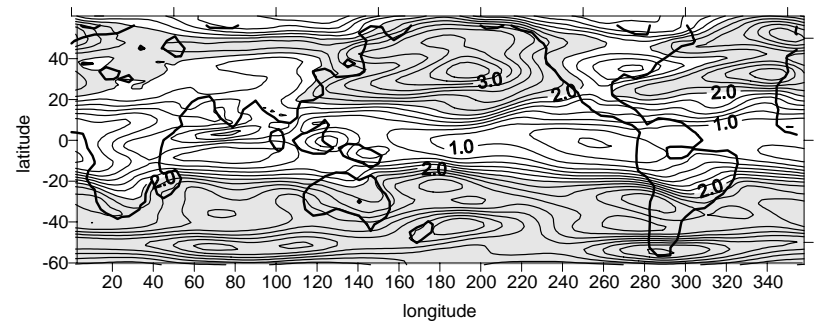

(f)

\section{PRECIP}

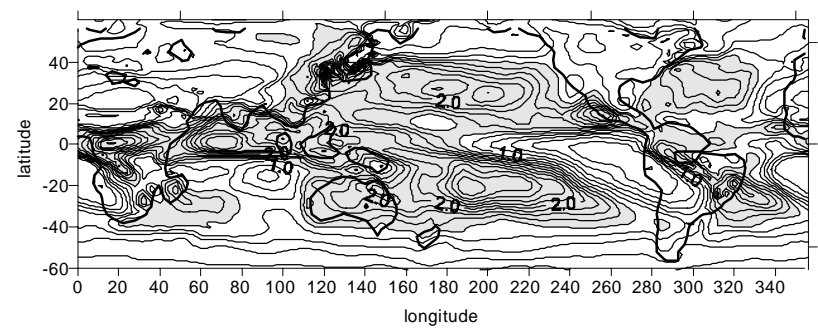

Fig. 2. Correlation (a, b, c) and rms difference (d, e, f) maps between CR and PAC experiments for zonal wind at $200 \mathrm{mb}(\mathrm{a}, \mathrm{d}), 850 \mathrm{hPa}(\mathrm{b}$, e) and precipitation (c, f) monthly anomalies. Correlation higher 0.3 are hatched. Rms difference larger than $5 \mathrm{~m} / \mathrm{s}(\mathrm{d}), 2 \mathrm{~m} / \mathrm{s}(\mathrm{e})$ and $2 \mathrm{~mm}$ (f) are shaded. Contour interval is $0.1(\mathrm{a}-\mathrm{c}) ; 1 \mathrm{~m} / \mathrm{s}(\mathrm{d}) ; 0.2 \mathrm{~m} / \mathrm{s}(\mathrm{e})$ and $0.2 \mathrm{~mm}(\mathrm{f})$.

land surface and atmospheric variables. The QTCM run corresponds to a standard configuration for model parameters Zeng et al. (2000) and hereafter referred to as CR. To estimate the tropical Pacific remote forcing, we performed the experiment PAC. It consists in forcing QTCM with the same initial SST data than CR, but with the interannual anomalies restricted to the tropical Pacific region (the forcing area is shaded on the Fig. 1) from January 1949 onward. PAC is the experiment where the full anomalies of the tropical Pacific were retained.

Similar experiments were carried out in other recent studies. Liu et al. (2004) analyzed the remote impact of tropical Pacific climate forcing on the tropical Atlantic sea surface temperature variability using a GCM model and provided the dynamic assessment of the impact of the corresponding forcing. Su and Neelin (2002) performed a similar experiment than PAC using QTCM to study the teleconnection mechanism in the zones of vertical motion negative anomalies during El Niño. Su et al. (2001) examined the response to various SST anomalies in the tropical oceans (tropical Pacific included) using previous version of QTCM (QTCM 2.1) in a case study of the impact of the El Niño 1997-1998. They analyzed the anomalous seasonal fields with respect to climato- logical annual cycle using the ensemble means for 10 experiments. This allowed for estimating the role of remote forcing versus local effect in reproducing the seasonal anomalous patterns of wind, precipitation and tropospheric temperature. In our study, we focus on the interannual variability patterns of various meteorological characteristics obtained from the $\mathrm{CR}$ and PAC experiments. Such method provides a qualitative estimate of how the contribution of remote tropical Pacific forcing versus local effects into the simulated anomalies changes in various regions of the tropics and subtropics.

The following diagnostics were calculated for $\mathrm{CR}$ and PAC: root mean square (rms) of the monthly means and of the monthly anomalies as well as Hovmullers plots for various meteorological parameters (zonal and meridional winds at 850,500 and $200 \mathrm{hPa}$, zonal wind stress, precipitation, OLR and net heat fluxes). To investigate the ENSO teleconnections, the lag-correlation between atmospheric fields and SST anomalies averaged over the NIÑO3 region (hereafter NIÑO3 SST Index) was calculated for two model experiments and the Reanalysis.

Simple statistical diagnostics (correlation and rms difference) were applied on the model simulations. Note, that on the correlation and rms difference maps, the regions of 
high correlation and small rms difference between CR and PAC correspond to the areas where the remote Pacific forcing plays an important role, while the regions with small correlation and high rms difference are the regions where remote forcing does not dominate.

\subsection{Results}

The map of correlation and rms-diff between CR and PAC for zonal wind are displayed on Figs. 2a, b, d, e. On the maps for low troposphere zonal wind (Fig. 2b) the areas of significant correlation (correlation value higher than 0.27 are significant at $95 \%$ ) spread from Indonesia through the whole equatorial Pacific (with two local maxima over the western and eastern Pacific) toward the equatorial Atlantic. The same feature is found for TX (not shown). Thus the low troposphere circulation response to the Pacific SST forcing is significant in the equatorial Pacific, South America, western and central equatorial Atlantic, while over the Indian Ocean the effect of the remote forcing is weak. This is consistent with the results by Su et al. (2001) which found that seasonal wind anomaly simulated in full SST and PAC SST experiments are similar to some extent over the equatorial Pacific, South America and equatorial Atlantic, but differ significantly over the Indian Ocean. Consistently with Gill (1980)'s interpretation, the wind anomalies are the response to the anomalous heating of the troposphere. Su et al. (2003ab) showed that during an El Niño event there are substantial tropospheric temperature anomalies across the tropics associated with sea surface temperature warming. The spatial pattern of tropospheric temperature response is wide-spread because of the effectiveness of wave dynamics in spreading the temperature anomalies. However the wind response to Pacific remote forcing is weak over the Indian Ocean. This is believed to be caused by local SST anomaly or teleconnections from other oceans. In the upper troposphere (Fig. 2a), one can observe the signature of PNA (Pacific North/American) teleconnection pattern with the correlation maxima forming the arc structure in both Hemispheres.

For the zonal wind fields, small rms difference values are observed over the whole tropics, while the maxima are located in the subtropical and mid latitudes. We can suggest that out of the tropics, the effect of remote Pacific forcing weakens and other processes, like weather random, local SST forcing and teleconnections from other regions dominate the variability. The weakening of the wind response in the subtropics is not surprising as the pattern of tropospheric temperature anomalies are spread across the globe but confined to the tropical belt, the latter being the main cause that produces the wind anomalies. We can also note the area of small rms difference spreading from the forcing region to the northeast in the low troposphere (Fig. 2e) and the belt of small rms difference in the mid latitudes of Northern Hemisphere (Figs. 2e, d). Although the effect of Pacific remote forcing is significant in these regions, the teleconnection mechanism associated to such pattern remains a subject of further investigation.
As the distribution of correlation and rms difference between PAC and CR for precipitation and OLR are almost identical, we present here the maps for precipitation only (Figs. 2c, f). It is not surprising that precipitation and OLR are perfectly correlated over the forcing regions, which means that convection and rainfall over the equatorial Pacific are almost completely determined by SST in the equatorial Pacific. This is not the case for the wind maps, where the correlation is high but lower than $80 \%$. Outside the forcing region, the correlation for precipitation and OLR is very weak, which indicates that convection and rainfall result from local interaction or random weather and are weakly influenced by the remote processes. However, one can detect a zone of significant correlation for precipitation over the northeastern Brasilia and Guinea golf (Fig. 2c). These regions experience maximum precipitation anomalies in summer 1997 (Guinea golf) and winter 1998 (North-eastern Brasilia) as a response to the positive tropical Pacific SST anomalies (Su et al., 2001). The influence of tropical Pacific SST on the precipitation over Brasilia may be caused by the change in the Walker and Hadley circulation cells associated to ENSO (Wang, 2002). The anomalies in the equatorial Atlantic result from significant remote Pacific forcing but also from Atlantic local SST anomalies (Su et al., 2001). However the latter is also controlled by the tropical Pacific SST (Covey and Hasternath, 1978; Latif and Barnett, 1995; Latif and Grotzner, 2000). For OLR, there is no correlation between $\mathrm{CR}$ and PAC over the Indian ocean, but significant correlation is found over the equatorial South America and Atlantic (not shown). This is due to the fact that the convection over the equatorial Atlantic is influenced by the tropical Pacific SST. Such characteristics are observed in the NCEP/NCAR Reanalysis (Gushchina and Dewitte, 2005), which illustrate the skill of QTCM in simulation the teleconnection pattern in the South-American monsoon system. For precipitation, the highest rms difference between CR and PAC is observed in the Indian monsoon region, the Southern Hemisphere Tropical Convergence Zone (SHTCZ) region and over the subtropical highs (Fig. 2f).

To summarize, we can note that within the tropics the difference between PAC and CR over the Indian Ocean are larger than over the Atlantic pointing to the fact that, in the Indian Ocean, the processes of local ocean-atmosphere interaction influence the interannual variability stronger than over the Atlantic where the remote forcing has more pronounced effect. The mechanisms of such remote forcing could be exerted through atmospheric bridge (Klein et al., 1999; Latif and Grotzner, 2000; Nobre and Shukla, 1996). However we should keep in mind that local air-sea interaction could enhance the effect of remote forcing. For instance, Liu et al. (2004) shows that the remote impact contributes to nearly half of the variance of the tropical Atlantic sea surface temperature variability at interannual time-scale. The detailed analysis of Pacific-Atlantic teleconnections using QTCM is the subject of our undergoing work (Illig and Dewitte, 2006; Illig et al., 2006). 
(a)

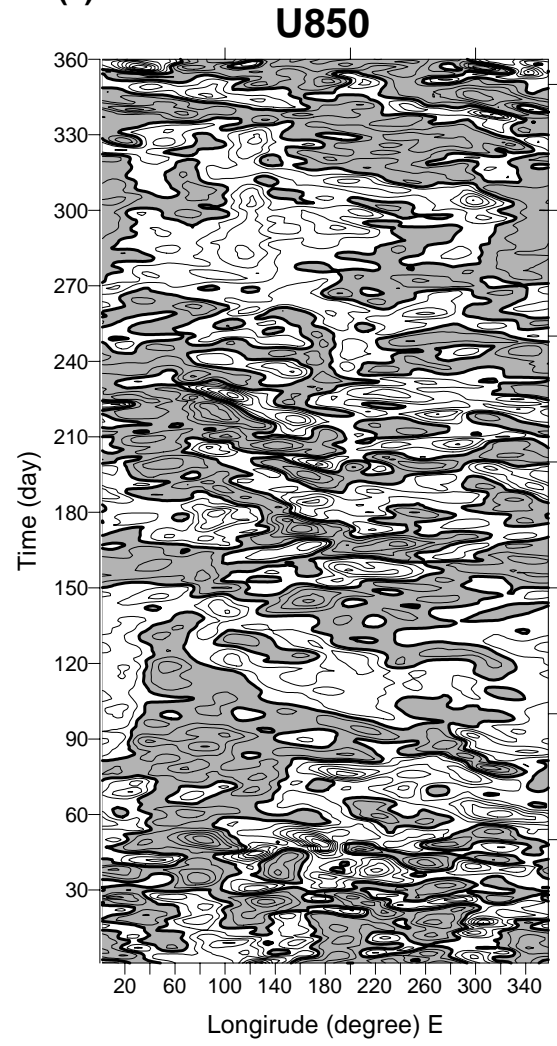

(b)

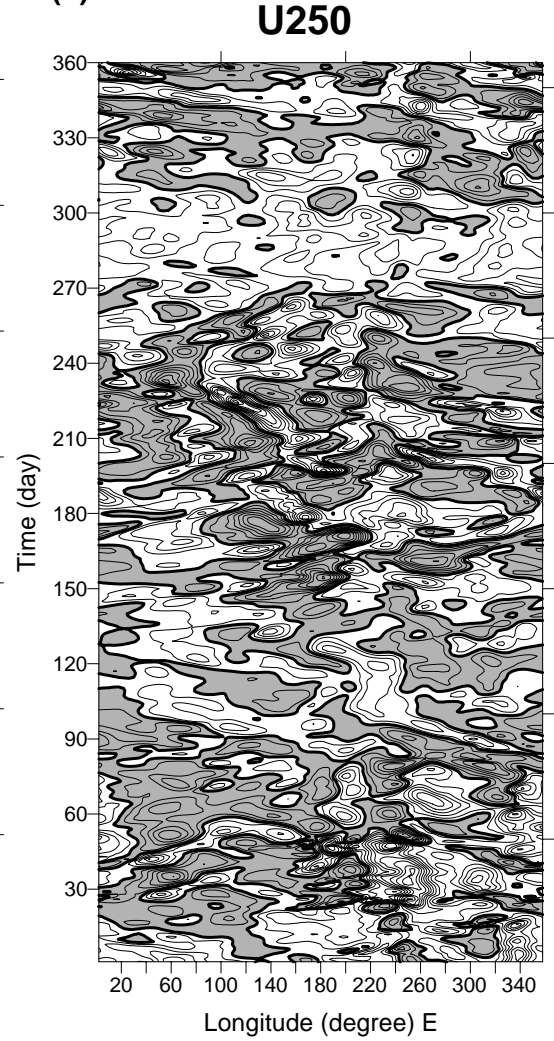

(c)

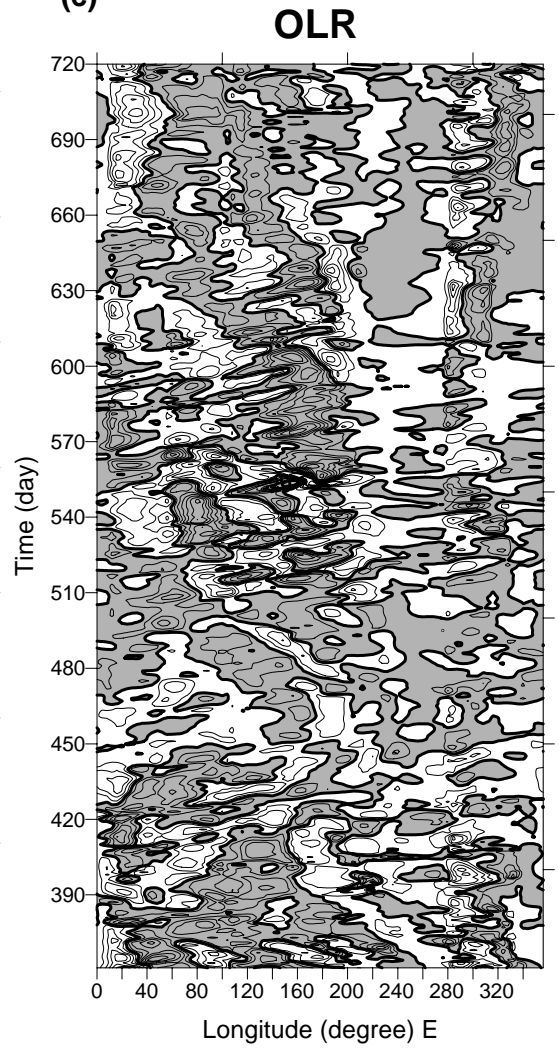

Fig. 3. Time-longitude plots of equatorial (averaged between $6.26^{\circ} \mathrm{N}-6.26^{\circ} \mathrm{S}$ ) daily-mean anomalies of (a) U850 (contour interval is $1 \mathrm{~m} / \mathrm{s}$ ), (b) U250 (contour interval is $2 \mathrm{~m} / \mathrm{s}$ ) and (c) OLR (contour interval is $5 \mathrm{~W} / \mathrm{m}^{2}$ ). Negative values are shaded. Day1 begins with the second year of the model run, the first year being discarded to remove any residual spinup effect. The results for the second year of the model run is shown for (a) and (b) and for the third year of the model run for (c).

\section{Sensitivity of the ENSO teleconnection characteristics to the intraseasonal variability}

\subsection{Description of the experiments}

It is commonly known that forced model results can vary depending on the model parameter values that are used. To analyze how the change of model parameters may affect the simulated teleconnection, a series of sensitivity tests was carried out. Rather than focusing on the direct impact of the parameter change onto a particular simulation (see Zeng et al. (2000) for results to sensitivity tests to parameter selection for the climatology), we investigate how the parameter change impacts the variability of the difference between the global forcing case (CR) and the Pacific forcing-only case (PAC). Note that Wu et al. (2002) suggest that intraseasonal tropical variability have a significant influence on the ENSO cycle. In this context we aim to estimate the role of intraseasonal variability (ITV) on the ENSO teleconnection patterns as simulated by QTCM (experiments CRWTIV and PACWTIV). The impact of intraseasonal variability produced by the model on our results was evaluated thanks to runs without evaporation-wind feedback and without the effect of extratropical excitation following the methodology described in Lin et al. (2000). Experiments are summarized in Table 1.

\subsection{Simulated intraseasonal variability}

We first described the ITV simulated by QTCM. Lin et al. (2000) analyzed the intraseasonal variability in an early version of QTCM 2.1 with climatological SST as a boundary forcing. They found that the model intraseasonal variability has rather realistic characteristics. We analyzed the characteristics of intraseasonal variability in the version of the model used in this study (QTCM2.3 with higher horizontal resolution). Following the same methodology than Lin et al. (2000) to derive the daily-average fields for the intraseaonal timescales, the Fig. 3 presents the Hovmullers plots of equatorially averaged daily anomalies for the zonal wind and OLR. Overall, the obtained results are in a good agreement with the results of Lin et al. (2000). The nature of the signal differs depending on the field.

The $850 \mathrm{hPa}$ zonal wind anomalies (Fig. 3a) demonstrate a tendency of a globally propagating signal with the phase speed depending on the season: $4 \mathrm{~m} / \mathrm{s}$ in northern autumn and winter, $7 \mathrm{~m} / \mathrm{s}$ in boreal summer and up to $12 \mathrm{~m} / \mathrm{s}$ during northern late winter - early spring. Additionally during northern summer the phase speeds vary longitudinally: from $3.7 \mathrm{~m} / \mathrm{s}$ in the western hemisphere over the central Africa, Indian ocean and Indonesia, i.e. over the region where the deep convection dominates, and up to $10.3 \mathrm{~m} / \mathrm{s}$ east of $170^{\circ} \mathrm{E}$, i.e. 
Table 1. Please give caption.

\begin{tabular}{lll}
\hline Experiment name & Boubary forcing & Other characteristics \\
\hline CR & SST worldwide & \\
PAC & SSTA restricted to the tropical Pacific & \\
CRWTIV & SST worldwide & Intraseasonal variability filtered out \\
PACWTIV & SSTA restricted to the tropical Pacific & Intraseasonal variability filtered out \\
\hline
\end{tabular}

over the eastern Pacific and Atlantic ocean where there is less climatological convection. During the northern winter and spring, the average phase speed is almost constant across the latitude circle. In northern autumn a minimum of intraseasonal variability is observed. All these features are consistent with the results obtained by Lin et al. (2000) with the earlier version of QTCM. The dominant phase speed of the propagating features in $850 \mathrm{hPa}$ zonal wind field is somewhat lower in the "new" version of the model. This could be due to the enhanced internal variability in the high resolution version which would tend to slow down the propagation of the high frequency signal. However the amplitude of anomalies is greater in the new version of model by a factor of 3 . This is in accordance with the results obtained for monthly anomalies which are greater than in the previous QTCM version by a factor of 1.5 , which is more realistic as suggested by a comparison with the Reanalysis (not shown). Another important difference of the new version is the appearance of westward propagating signal. During northern winter and spring, this propagation pattern is observed in the western hemisphere (to the east of $160^{\circ} \mathrm{E}$ ) with the phase speed around $5 \mathrm{~m} / \mathrm{s}$. From early winter, it propagates over the Indonesia, western and central Pacific with a slightly higher speed about $6.5 \mathrm{~m} / \mathrm{s}$. It may be related to the westward propagating synoptic-scale disturbances within the intertropical convergence zone, visible in time-longitude plots of cloudiness (Chang, 1970).

In contrast the upper troposphere zonal wind anomalies (Fig. 3b) do not exhibit propagations all around the globe. In northern winter and summer, anomalies develop over the Indian Ocean, extend eastward and disappear around the date line. Outside of these regions there is no significant variability with coherent propagating characteristics, consistently with Lin et al. (2000). The maximum of variability occurs in northern summer and early autumn. The second maximum appears in February-March (January-February in previous version). The minimum is generally presented around September-October. The phase speed varies depending of the season and longitude. In the northern winter the anomalies propagates eastward with speed from $3.7 \mathrm{~m} / \mathrm{s}$ up to $5.1 \mathrm{~m} / \mathrm{s}$ and stop at the date line. In northern spring the anomalies propagate westward with higher phase speed $(8.5 \mathrm{~m} / \mathrm{s})$ in the beginning of spring and slower speed $(5 \mathrm{~m} / \mathrm{s})$ in April. In the northern summer, we can observe both the eastward and westward propagating anomalies. The first one has a phase speed varying with longitude: slower $(4.5 \mathrm{~m} / \mathrm{s})$ in the west, in the region of high climatological convection, and faster
$(11.2 \mathrm{~m} / \mathrm{s})$ in the east, in the regions of weak climatological convection. The westward propagating anomalies are observed across the globe with the slow phase speed around 2-3 m/s. However they do not propagate around Earth's circumference at the equator, but usually do not extend as much as $60-80$ degrees. In northern autumn, there is no propagating signal in the upper troposphere zonal wind field and in the early winter, the fast westward propagating patterns appear. The amplitude of upper troposphere zonal wind anomalies are twice higher as compare to the previous version (the same increasing is observed for interannual upper troposphere zonal wind variability).

For ORL anomalies (Fig. 3c), the highest amplitudes occur over the Indian ocean, Indonesia, western and central Pacific (between $80^{\circ} \mathrm{E}$ and $160^{\circ} \mathrm{W}$ ). In QTCM2.1, the OLR anomalies are shifted to the west compared to QTCM2.3 and are observed between $0-180^{\circ} \mathrm{E}$. The maximum activity appears in the northern summer versus summer-autumn in the previous version. The phase speed does not change a lot with longitude and season and is about $7-8 \mathrm{~m} / \mathrm{s}$ (instead of $5-10 \mathrm{~m} / \mathrm{s}$ in QTCM2.1). The amplitude of the anomalies is higher by a factor of 3 as compared to the previous version, consistently with the increase in the amplitude of the monthly OLR anomaly as observed in QTCM2.3 In northern winter the westward propagating patterns appear in the eastern hemisphere with characteristic phase speed about $2 \mathrm{~m} / \mathrm{s}$. As was mentioned above they may be related to the westward propagating synoptic-scale disturbances within the intertropical convergence zone. Note however that the characteristics described above may vary significantly from one model year to the other.

\subsection{Sensitivity to the intraseasonal variability}

Lin et al. (2000) demonstrated that the major sources of energy for the intraseasonal variability in the QTCM model are the evaporation-wind feedback and the extratropical excitation by the mid-latitudes storms variability, the latter being the main contributor to the tropical ITV. Following their methodology, the experiments where these two effects are turned off are carried out. The results are compared to the standard case for U850 (Fig. 4).

In the standard case (ITV not "filtered"), the difference between CR and PAC for the low troposphere zonal wind in the subtropics and mid latitudes is of the order of the rms of the total field and three times smaller in the near equatorial 
(a)

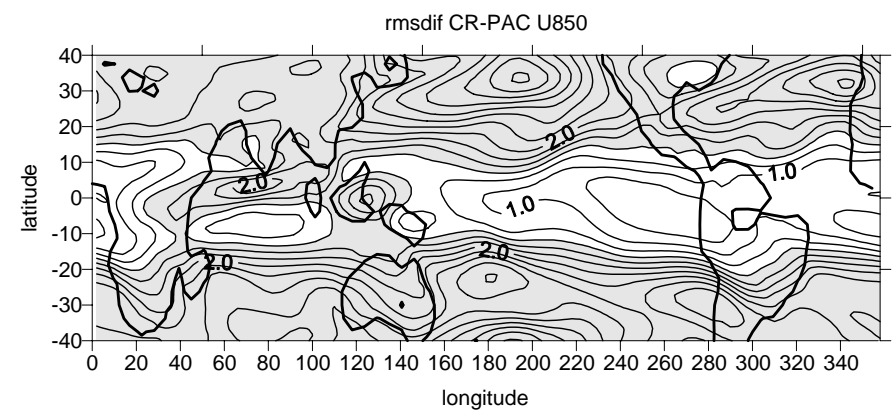

(b)

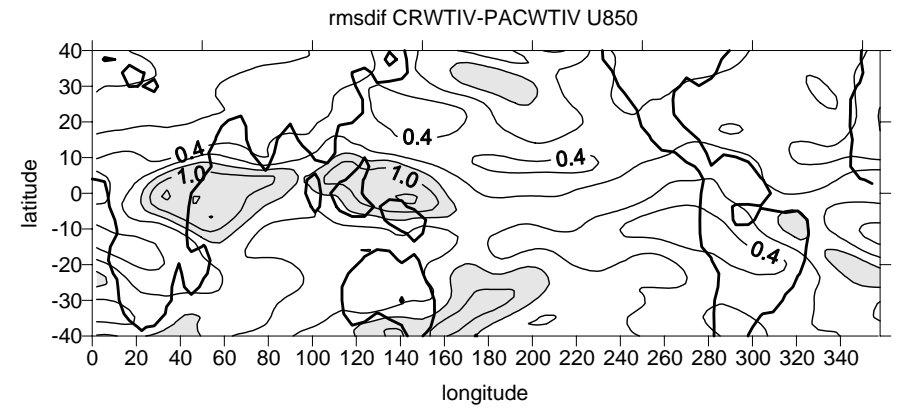

(c)

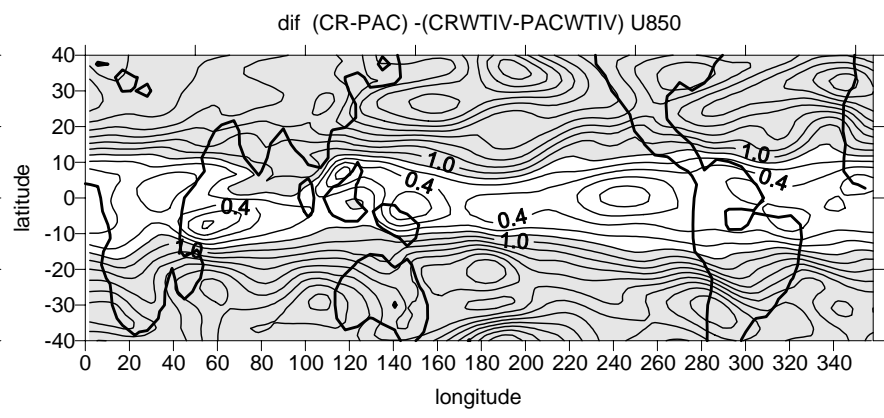

(d)

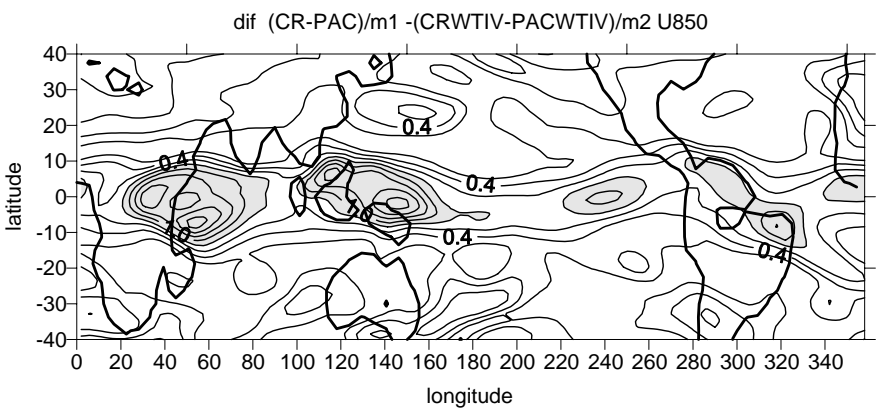

Fig. 4. Maps of rms difference for the $850 \mathrm{hPa}$ zonal wind (a) between CR and PAC, (b) between CRWTIW and PACWTIV; difference (c) between (a) and (b); (d) same as (c) but normalized by the mean of the difference between CR and PAC (m1), and the mean of the difference between CRWTIV and PACWTIV (m2) respectively.

region $\left(10^{\circ} \mathrm{N}-10^{\circ} \mathrm{S}\right)$ with however two maxima located over the Indonesia and equatorial Indian ocean (Fig. 4a). This illustrates that outside the tropics the effect of remote Pacific forcing is weak and that other processes like random weather noise and local air-sea interaction contribute to the interannual variability of the wind. The experiments $C R$ and PAC also confirm that within the tropical belt the remote forcing is significant in tropical Atlantic and equatorial Indian oceans, while it has a weaker influence over Indonesia and the Northern tropical Indian Ocean.

When the ITV is turned off in QTCM (Fig. 4b), the difference for the surface circulation between PACWTIV and CRWTIV in the subtropics and midlatitudes is small, traducing that mid-latitude storms activity dominates the variability in these regions. Note however three maxima in the rms difference maps in the subtropics: to the east of Australia, in the northern Pacific and in the South Atlantic. These regions correspond to the trade-wind fronts where the local air-ocean interaction is strong and as a consequence, the remote forcing is less pronounced. Noteworthy, the ITV effect is not significant for the interannual variability in the trade-wind front areas.

Over the tropics, the maxima of rms difference between CRWTIV and PACWITV are located almost over the same regions as in the "standard" case (PAC-CR rms difference) (Figs. 4a, b). Therefore within the tropics, ITV does not have a significant impact on the ENSO teleconnection. This also shows up from Fig. $4 \mathrm{c}$ where the difference between the fields of the maps of Fig. 4a and Fig. 4b is presented. Within the tropics, the difference is small and outside it is large. This indicates that the simulated ITV has a strong impact on the model teleconnection in the subtropical and mid-latitudes, whereas within the tropical belt no significant changes are detected. This statement however should be moderated by the fact that, when the ITV is turned off, the magnitude of rms difference between PAC and CR is smaller an average by the factor of 3 , which can hide regional peculiarities. In order to highlight the difference within the tropics, the rms difference maps were normalized by the mean of the difference between CR and PAC, and CRWTIV and PACWTIV respectively. The difference is presented in Fig. 4d. The maxima are then observed over the Western Indian ocean, Indonesia and Western Pacific, eastern Pacific, North-eastern Brazil and equatorial Africa. These regions correspond to the location of the ascendant and descendent branches of the Walker equatorial zonal circulation cell (Wang, 2005), indicating that in QTCM, the simulated zonal wind interannual variability is sensitive to the ITV in these regions. As the Walker circulation cells are part of the tropical teleconnection mechanism (Wang, 2005), this suggests a potential role of ITV in the tropical teleconnection in QTCM. 


\section{Conclusions}

Consistently with former studies (Zeng and Neelin, 2000; Sue et al., 2001, 2002, 2003a, b; Gushchina and Dewitte, 2005), we have shown that QTCM, although with simpler physics than most AGCM, simulate the dominant aspects of the ENSO teleconnection pattern over the globe. In particular, within the tropics, the wind anomalies, associated to the anomalous warming of the troposphere, are simulated by the model, as well as convection anomaly patterns over the South American continent and the equatorial Atlantic.

Lin et al. (2000) proposed a methodology in order to damp the energy of ITV in the model. Using this methodology, we investigate the sensitivity of the simulated ENSO teleconnection pattern to ITV. As expected the reduction of intraseasonal variability allows emphasizing the forced response of the atmosphere and eases the detection of local coupled atmosphere-ocean patterns. Similar results could be obtained from ensemble experiments but it would be computationally more expensive. Interestingly, the simulated ITV has an impact on the ENSO teleconnection pattern both in the mid-latitudes and in regions of ascending and descending branches of Walker circulation cells in the tropics. As ITV is a component of the tropical Pacific system and ENSO (Zavala-Garay et al., 2005), this illustrates the potential of QTCM for ENSO coupled studies. While cost effective coupling procedure using ensemble experiments are being developed (Wu and Kirtman, 2003), QTCM offers to opportunity to investigate more easily the statistical significance of air-sea coupling in tropical regions in a coupled framework (Illig et al., 2006).

The perspective of this work includes a more refined validation of the ITV of the model and the use of a linear model of the Pacific and Atlantic oceans to couple to QTCM in order to study tropical Atlantic response to ENSO forcing.

Acknowledgements. This work was supported by the grant RFBS (No.05-05-65032). Dr. Gushchina was supported by the INTAS YS Fellowship (Ref. Nr. 03552239). NCEP/NCAR Reanalysis data used in this study have been provided by NCEP.

Edited by: P. Fabian and J. L. Santos

Reviewed by: H. Dijkstra and another anonymous referee

\section{References}

Barnett, T. P., Bengtsson, L., Arpe, K., et al.: Forecasting global ENSO-related climate anomalies, Tellus A, 46, 381-397, 1994.

Betts, A. K. and Miller, M. J.: A new convective adjustment scheme. Part II: Single column tests using GATE wave, BOMEX, ATEX and arctic air-mass data sets., Quart. J. R. Met. Soc., 112, 693-709, 1986.

Chang, C. P.: Westward propagating cloud patterns in the tropical Pacific as seen from time composite satellite photographs, J. Atmos. Sci., 27, 133-138, 1970.

Chang, P., Saravanan, R., Ji, L., and Hegerl, G. C.: The effect of local sea surface temperatures on atmospheric circulation over the tropical Atlantic sector, J. Climate, 13, 2195-2216, 2000.
Covey, D. L. and Hastenrath, S.: Pacific El Niño Phenomenon and Atlantic circulation, Mon. Wea. Rev., 106, 1280-1287, 1978.

Enfield, D. B. and Mayer, D. A.: Tropical Atlantic sea surface temperature variability and its relation to El Nino-Southern Oscillation, J. Geophys. Res., 102, 929-245, 1997.

Gill, A. E.: Some simple solutions for heat induced tropical circulation, Q. J. R. Metorol. Soc., 106, 447-462, 1980.

Gushchina, D. and Dewitte, B.: Interannual climate variability and teleconnections in the quasi-equilibrium tropical circulation model, Izvestiya RAN, Physics of atmosphere and ocean, 41, 435-463, 2005.

Hastenrath, S., de Castro, L. C., and Aceituno, P.: The Southern Oscillation in the tropical Atlantic sector, Beitr. Phys. Atmos., 60, 447-463, 1987.

Illig, S., Dewitte, B., Ayoub, N., duPenhoat, Y., Reverdin, G., DeMey, P., Bonjean, F., and Lageloef, G. S. E.: Interannual long equatorial waves in the tropical Atlantic from a high resolution OGCM experiment in 1981-2000, J. Geophys. Res., 109(C2), C02022, doi:10.1029/2003JC001771, 2004.

Illig, S. and Dewitte, B.: Local Coupled Equatorial Variability Versus Remote ENSO Forcing in an Intermediate Coupled Model of the Tropical Atlantic, J. Climate, accepted, 2006.

Illig, S., Gushchina, D., Dewitte, B., Ayoub, N., and duPenhoat, Y.: The 1996 Equatorial Atlantic warm event: origin and mechanisms, Geophys. Res. Lett., accepted, 2006.

Kalnay, E., Kanamitsu, M., Kistler, R., et al.: The NCEP/NCAR 40year reanalysis project, Bull. Amer. Meteor. Soc., 77, 437-471, 1996.

Klein, S. A., Sooden, B. J., and Lau, N.-C.: Remote sea surface temperature variations during ENSO: Evidence for a tropical atmospheric bridge, J. Climate, 12, 917-932, 1999.

Kumar, A. and Hoerling, M. P.: Specification on regional sea surface temperature in the atmospheric general circulation model simulations, J. Geophys. Res., 103, 8901-8907, 1998.

Latif, M. and Barnett, T.: Interactions of the tropical oceans, J. Climate, 8, 952-964, 1995.

Latif, M. and Grotzner, A.: The equatorial Atlantic oscillation and its response to ENSO, Clim. Dyn., 16, 213-218, 2000.

Lau, N.-C.: Modeling the seasonal dependence of the atmospheric response to observed El Niños in 1962-76, Mon. Wea. Rev., 113, 1970-1996, 1985.

Lau, N.-C.: Interactions between global SST anomalies and the midlatitude atmospheric circulation, Bull. Amer. Meteor. Soc., 78, 21-33, 1997.

Lin, J. W.-B., Neelin, J. D., and Zeng, N.: Maintenance of tropical intraseasonal variability: Impact of evaporation-wind feedback and mid-latitude storms, J. Atmos. Sci., 57, 2793-2823, 2000.

Liu, Z., Zhang, Q., and Wu, L.: Remote impact on tropical Atlantic climate variability: Statistical assessment and dynamic assessment, J. Climate, 17, 1529-1549, 2004.

Madden, R. A. and Julian, P. R.: Observations of the 40-50 day tropical oscillation - A review, Mon. Wea. Rev., 122, 814-837, 1994.

Marshall, J., Kushnir, Y., Battisti, D., et al.: North Atlantic climate variability: Phenomena, impacts and mechanisms, Int. J. Climatol., 21, 1863-1898, 2001.

Neelin, J. D. and Zeng, N.: The first quasi-equilibrium tropical circulation model-formulation, J. Atmos. Sci., 57, 1741-1766, 2000.

Nobre, P. and Shukla, J.: Variations of sea surface temperature, wind stress, and rainfall over the tropical Atlantic and South America, J. Climate, 9, 2464-2479, 1996. 
Palmer, T. N., Brankovic, C., Viterbo, P., and Miller, M. J.: Modeling interannual variations of summer monsoons, J. Climate, 5, 399-417, 1992.

Rasmusson, E. M. and Carpenter, T. H.: The relationships betweeneastren equatorial Pacific SSTs and rainfall over India and Sri Lanka, Mon. Wea. Rev., 111, 517-528, 1983.

Rayner, N. A. and co-authors: Version 2.2 of the Global Sea-Ice and Sea Surface Temperature data set, 1903-1994, CRTN 74, 21 pp, available from the Hadley Centre, UKMO, Bracknell, Berks, 1997.

Ropelewki, C. F. and Halpert, M. S.: Global and regional scale precipitation associated with El Nino/Southern Oscillation, Mon. Wea. Rev., 115, 1606-1626, 1987.

Saravanan, R. and Chang, P.: Interaction between tropical Atlantic variability and El Niño-Southern Oscillation, J. Climate, 13, 2177-2194, 2000.

Su, H., Neelin, J. D., and Cou, C.: Tropical teleconnection and local response to SST anomalies during the 1997-1998 El Niño, J. Geophys. Res., 106, 20 025-20 043, 2001.

$\mathrm{Su}, \mathrm{H}$. and Neelin, J. D.: Teleconnection mechanisms for tropical Pacific descent anomalies during El Niño, J. Atmos. Sci., 59, 2694-2712, 2002.

Su, H., Neelin, J. D., and Meyerson, J. E.: Tropical tropospheric temperature and precipitation response to sea surface temperature forcing, in: Ocean-Atmosphere Interaction and Climate Variability, edited by: Wang, C., Xie, S.-P., and Carton, J., Amer. Geophys. Union, 379-392, 2003a.

Su, H., Neelin, J. D., and Meyerson, J. E.: Sensitivity of tropical tropospheric temperature to sea surface temperature forcing, J. Climate, 16, 1283-1301, 2003b.

Trenberth, K. E., Branstator, W. B., Karoly, D., Kumar, A., Lau, N.C., and Ropelewski, C.: Progress during TOGA in understanding and modeling global teleconnections associated with tropical sea surface temperatures, J. Geophys. Res., 103, 14 291-14324, 1998.
Wallace, J. M. and Gutzler, D. S.: Teleconnections in the geopotential height field during the Northern Hemisphere winter, Mon. Wea. Rev., 115, 3078-3096, 1981.

Wallace, J. M., Rasmusson, E. M., Mitchell, T. P., Kousky, V. E., Sarachik, E. S., and von Storch, H.: On the structure and evolution of ENSO-related climate variability in the tropical Pacific: Lessons from TOGA, J. Geophys. Res., 103, 14241-14260, 1998.

Wang, C.: Atmospheric circulation cells associated with the El Niño-Southern Oscillation, J. Climate, 15, 399-419, 2002.

Wang, C.: ENSO, Atlantic climate variability, and the Walker and Hadley circulations, in: The Hadley Circulation: Present, Past, and Future, edited by: Diaz, H. F. and Bradley, R. S., Kluwer Academic Publishers, 173-202, 2005.

Webster, P. J., Magana, V. O., Palmer, T. N., Shukla, J., Tomas, R. A., Yanai, M., and Yasunari, T.: Monsoons: Processes, predictability and the prospects for prediction, J. Geophys. Res., 103, 14 451-14 510, 1998.

$\mathrm{Wu}, \mathrm{R}$. and Kirtman, B. P.: On the impacts of the Indian summer monsoon on ENSO in a coupled GCM, Quart. J. Roy. Meteor. Soc., 129B, 3349-3468, 2003.

Wu, M. L. C., Schubert, S. D., Kang, I.-S., and Waliser, D.: Forced and Free intraseasonal variability over the South Asian Monsoon region simulated by 10 AGCMs, J. Climate, 15, 2862-2880, 2002.

Yulaeva, E. and Wallace, J. M.: The signature of ENSO in global temperature and precipitation fields derived from microwave sounding unit, J. Climate, 7, 1719-1736, 1994.

Zavala-Garay, J., Zhang, C., Moore, A. M., and Kleeman, R.: The Linear Response of ENSO to the Madden-Julian Oscillation, J. Climate, 18, 2241-2459, 2005.

Zeng, N., Neelin, J. D., and Chou, C.: The first quasi-equilibrium tropical circulation model-implementation and simulation, J. Atmos. Sci., 57, 1767-1796, 2000. 